\title{
Assessing the Economic Efficiency of Maize Production in Northern Ghana
}

\author{
Shamsudeen Abdulai \\ University for Development Studies, Tamale Ghana \\ Paul Kwame Nkegbe \\ University for Development Studies, Campus, Ghana \\ nkegbe@uds.edu.gh \\ and \\ Samuel A. Donkor \\ University for Development Studies, Tamale, Ghana \\ sdonkoh@uds.edu.gh \\ DOI//http://dx.doi.org/10.4314/gjds.v14i1.7
}

\begin{abstract}
This study used the stochastic frontier model to examine the technical, allocative and economic efficiency of maize production in northern Ghana using cross-sectional data for the 2011/2012 cropping season. Conventional inputs such as farm size, seed, fertilizer, labour and weedicides were statistically significant and had positive effects on maize output in northern Ghana using the Cobb-Douglas functional form. The mean estimates were $85.1 \%, 87.8 \%$ and $74.7 \%$ for technical, allocative and economic efficiencies respectively. Largely, maize production in the study area exhibited increasing returns to scale. The determinants of technical inefficiency were experience, agricultural extension service and gender. Farmers with many years of experience in maize production were more technically efficient and opportunities that bring the less experienced farmers to tap the accumulated knowledge of the more experienced ones would improve maize production. Farmers who had access to agricultural extension services were more technically efficient than those who did not have access and strengthening the extension service would further enable them improve on their technical efficiency. Male farmers were more technically efficient than females in maize cultivation and efforts that stress gender equality as regards access to economic resources, information and decision-making would help narrow this gap. There is allocative inefficiency relative to all the production inputs under the prevailing prices. Land, seed and weedicides would be allocatively efficient by increasing their use by $26.6 \%, 10.52 \%$ and 39.9\% respectively. Fertilizer and labour are currently being over-used and requires $82.8 \%$ and $94.5 \%$ reductions respectively to reach their allocatively efficient points.
\end{abstract}


Keywords: Stochastic Frontier Analysis, Technical Efficiency, Allocative Efficiency, Economic Efficiency, Maize, Northern Ghana

Abbreviations: AE - allocative efficiency; DHS - Demographic and Health Survey; EE - economic efficiency; FAO - Food and Agriculture Organization; GDP - Gross Domestic Product; GLSS - Ghana Living Standards Survey; GSS - Ghana Statistical Service; IRS - Increasing Returns to Scale; MDG - Millennium Development Goal; METASSIP - Medium Term Agriculture SubSector Investment Plan; MoFA - Ministry of Food and Agriculture; SSA - Sub-Saharan Africa; TE - Technical Efficiency.

\section{Introduction}

Almost all of Africa's poor rural population to a large extent depends on farming, and for that matter agricultural growth should be a core component of any development strategy that aims at reducing poverty and hunger in Africa (Thirtle et al., 2003). The successes of the green revolution in Asia brought to the fore agriculture's growth potential. The introduction of output enhancing technologies such as improved seeds for cereals like maize, and use of agrochemicals raised agriculture productivity and transformed it into a modern sector in Asia. According to Smith et al. (1997) and FAO (2006), maize is one of the staple foods of communities in the drought prone countries in sub-Saharan Africa (SSA) where over 650 million people consume annually an average of $43 \mathrm{~kg}$ of maize/person. The demand for maize for food, animal feed, and industrial use is increasing rapidly due to population growth across the region. Increasing the productivity of maize cropping systems is strategically important for the food security and socioeconomic stability of these countries and the sub-region as a whole. Abdoulaye et al. (2011) noted that more than $50 \%$ of all SSA countries assign more than half of the area planted to cereals to the production of maize only. In West Africa, maize is also a major source of food and cash for smallholder farmers (Abdoulaye et al., 2011). Nonetheless, recurring droughts, the use of unimproved seeds, soil fertility depletion, pests and diseases pose a continuous challenge to its production. Other common problems faced by farming households which are also detrimental to agricultural productivity include long distances to input markets, bad road networks and therefore attempts made at addressing these constraints will enhance maize production.

\section{Maize Production in Ghana}

The aim of Ghana's Medium Term Agriculture Sector Investment Plan (MoFA, 2010) is to modernise agriculture which will culminate in a structurally transformed economy evident in food security, employment opportunities and poverty reduction. To this end, Ghana's investment plan is to achieve an agricultural GDP growth of at least $6 \%$ annually and which also requires at least $10 \%$ of government's total expenditure allocation to 
achieve growth rates necessary to meet the goal of poverty and hunger eradication. Agriculture in Ghana is dominated by small scale producers who account for about $80 \%$ of domestic production. Yields of most crops are generally low (20-60\% below their achievable level), for example, cassava is at $12.4 \mathrm{mt} /$ ha against a potential yield of 28.omt/ha (MoFA, 2011).

Maize is a very important staple food in Ghana accounting for more than $50 \%$ of total cereal production in the country and grown in all agro-ecological zones (Akramov et al., 2012). The bulk of maize produced goes into food consumption and it is arguably the most important food security crop with a per capita consumption of $43.8 \mathrm{~kg} / \mathrm{head}$ in 2005 (MoFA, 2011). Even though average yield has been rising, from 1.5mt/ha in 2005/07 to $1.7 \mathrm{mt} / \mathrm{ha}$ in $2008 / 10$, this yield is less than a third of the achievable yield of $6.0 \mathrm{mt} / \mathrm{ha}$. This therefore requires an increase in productivity per hectare to close the yield gap in order to spur up agricultural growth.

Besides increasing land under maize cultivation, agricultural growth can also be achieved by improving the technical and allocative efficiencies of farming households in maize cultivation. Technical efficiency (TE) is the ability of a firm to achieve maximum output from a given set of inputs under a given technology, while allocative efficiency $(A E)$ is the ability of a firm to operate at optimum input levels given their respective factor prices in the production process. The product of TE and $A E$ is economic efficiency $(E E)$.

Maize production is largely dependent on farmers' efficiency which is also a function of their socio-economic indicators and farm characteristics. Even though a number of studies have been carried out on technical and allocative efficiencies, it is imperative to note that efficiency studies are time, location and even crop specific, hence the need for this study to delve further into the efficiency of maize production in northern Ghana. The main objective of this study was to investigate the levels and determinants of economic efficiency of maize farmers in northern Ghana. Specifically, the study sought to determine the levels as well as the factors influencing TE, $A E$ and $E E$ of maize farmers. Thus, the outcome of the study would give an indication of output relative to input use and input prices by maize farmers which could guide policy on how to increase the use of productive resources to achieve food sustainability as there is often a strong interrelationship between food insecurity and poverty. For instance, the 2008 Demographic and Health Survey (DHS) conducted by the Ghana Statistical Service (GSS) reported that, $18.2 \%$ of Ghanaians who fell below the extreme poverty line were chronically food insecure. A sustained growth in agriculture is therefore crucial to eradicating hunger, food insecurity as well as poverty and considering the fact that majority of Ghanaians smallholders grow and consume maize, any technology that would lead to an increase in productivity of inputs for maize cultivation would bring about real income gains for the 
rural population. To the extent that increases in productivity are translated into lower prices for maize, the income gains would also be passed on to urban dwellers.

\section{Materials and Methods}

\section{Study Area, Data and Sampling Approach}

The data were collected between January and February, 2013 in the three regions (Northern, Upper East and Upper West) of northern Ghana for the 2011/2012 cropping season. The three regions of northern Ghana (refer to Figure 1) together make up about $41 \%$ of the country's total land area (MoFA, 2011).

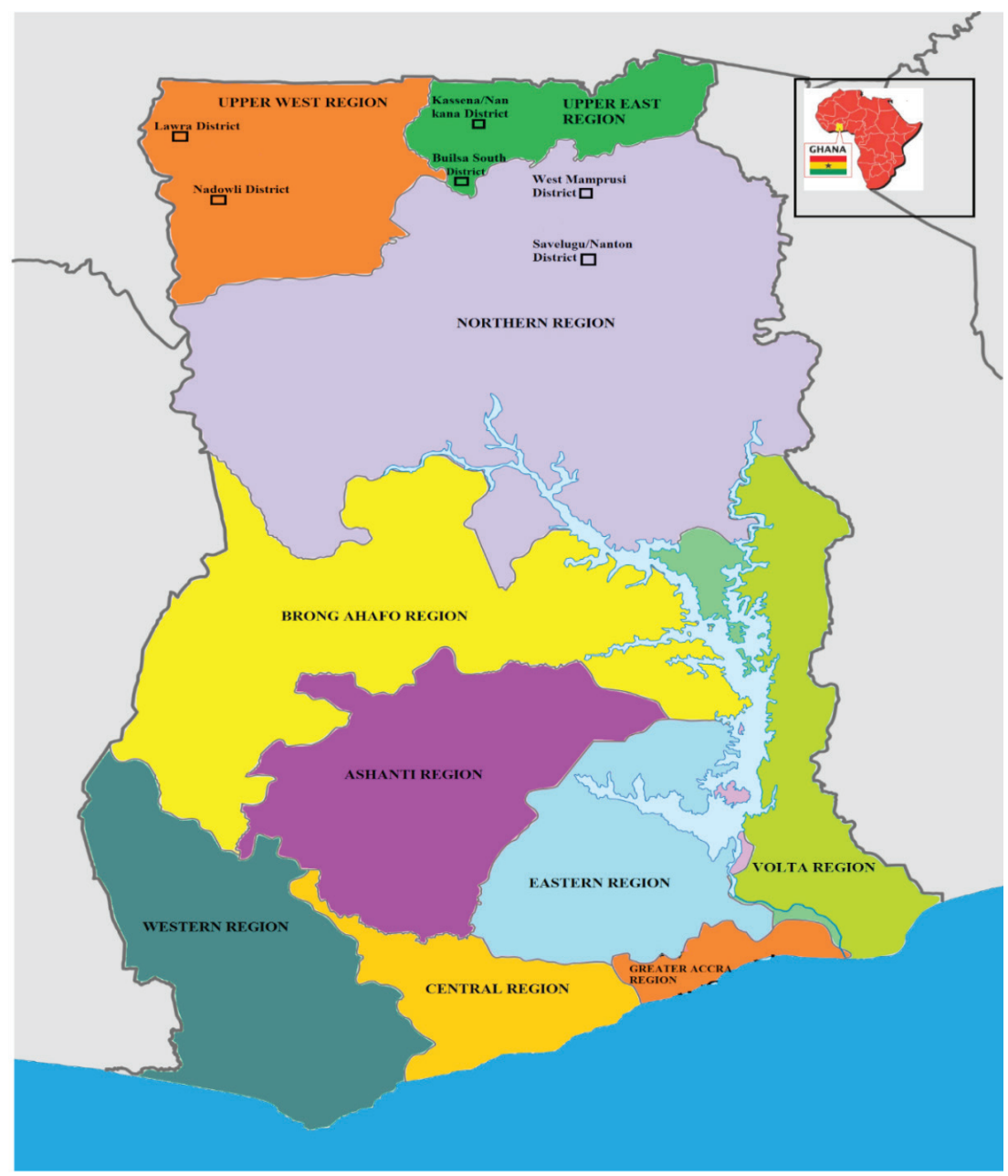

\section{Figure 1: A Map of Ghana showing the Study Area}

Source: Authors, 2015 
In terms of population, the three regions constitute only about $17 \%$ of the country's population (GSS, 2012). Amongst the three regions, Northern Region has the largest population and land size while the Upper West Region has the least population (GSS, 2012). Rainfall distribution in the three regions is unimodal giving a single growing season of about $180-200$ days with an annual mean of 1,100mm. The dry season starts in November and ends in March/April with maximum temperatures of about 42 degrees Celsius occurring towards the end of the dry season.

The data collection was carried out in six districts in northern Ghana, two districts in each of the three regions. Multi-stage sampling method was used in identifying a district where six communities were randomly selected in each district (giving a total of 36 communities). From each community 10 maize households were also randomly sampled to obtain a total of 60 respondents for each district. Each region had a sample size of 120 respondents, thus a total sample size of 360 maize households were considered from the three regions for the study.

It should be stated that the sample farms can be treated as a homogenous group for the following reasons. First and foremost, all the farms are in an area (northern Ghana) where technical and agronomic recommendation domains are the same and virtually produce maize as a mono-crop using the same production technology. Secondly, they are in close proximity to each other. Thirdly, all of the farmers face similar natural and market conditions and infrastructure. Finally, all the farms have broadly the same weather and or climate pattern.

\section{Theoretical Framework of Technical, Allocative and Economic Efficiencies}

This section explains the concepts of both production and efficiency and how the two concepts help us to understand the relationship between inputs and output under a given production technology. Production is defined as the transformation of resources (inputs) into finished products (outputs). A production function shows the relationship between inputs and output levels under a given technology. According to Johnes (2006), there are mainly two basic ways of estimating a production function for efficiency analysis, namely; the statistical (or econometric) approach and the nonstatistical (or programming approach). The statistical (econometric) methodology specifies a distributional assumption as well as a functional form and separates the effect of random (measurement) error outside the control of the farmer from the inefficiency component. The non-statistical and non-parametric approach such as the data envelopment analysis does not make assumptions regarding the distribution of inefficiencies or the functional form of the production function albeit it does impose some technical restrictions such as monotonicity and convexity (Kumbhakar et al., 
2000). The parametric approach, specifically the stochastic frontier is the main focus of this study. The concept of frontier is very important for the analysis of efficiency, in that efficiency is measured as the relative distance to the frontier. When measuring efficiency, a production function is used.

Efficiency is the act of achieving good result with little waste of effort. Efficiency measurement is very important because it is a factor for productivity growth. $T E$ is the ability of a firm to obtain maximum output from a given set of inputs. Thus, technical inefficiency occurs when a given set of inputs produces less output than what is possible given the available production technology. $A E$ refers to the ability to produce a given level of output using cost-minimising input ratios. $A E$ deals with the extent to which farmers make efficient decisions by using input up to the level at which their marginal value product (MVP) is equal to the marginal factor cost $(M F C)$ or price of input (Abdulai \& Huffman, 2000). A graphical illustration of $T E, A E$ and $E E$ is presented in Figure 2.

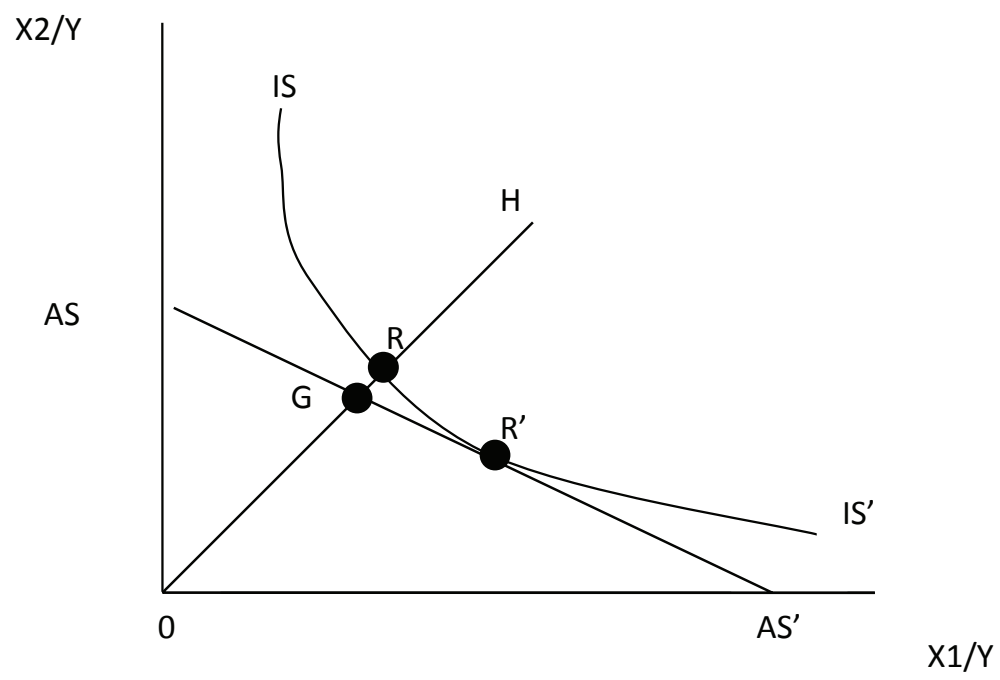

\section{Figure 2: Technical, Allocative and Economic Efficiency (Adapted from Coelli, 1996).}

From Figure 2, a firm operating at $R$ is technically efficient because it is operating on the isoquant IS-IS. However, if a firm is operating at $H$ it is not efficient because it is far away from $R$. In this regard, the technical inefficiency of $H$ is measured by the distance $R H$, which is the amount by which the firm's inputs can be proportionally reduced without reducing output. Thus, in a ratio form $T E$ of this firm is measured by $T E_{i}=O R O H$ which is equal to $1-R H / O H$. TE takes a value between zero and one. Thus a TE of one implies that the firm is fully efficient (while zero efficiency implies the firm has no $T E$ ). From the diagram, the input price ratio is represented by the slope of the straight line $A S-A S^{\prime}$. With this, the $A E$ of the firm can be determined. At point $H, A E$ is defined as 
the ratio $A E_{i}=O G /$ since the distance $G R$ represents the reduction in (production) costs if production were to occur at the allocatively (and technically) efficient point $R^{\prime}$ instead of the technically efficient, but allocatively inefficient point $R$. The product of TE and $A E$ is EE given as:

$$
E E=T E_{i} \times A E_{i}=(O R / O H) \times(O G / O R)=(O G / O H)
$$

\section{The Stochastic Frontier Function}

The stochastic frontier model was developed by Aigner, Lovell and Schmidt (1977), and Meeuseen van den Broeck (1977) building on previous work done by Farrell (1957) as well as Aigner and Chu (1968). The stochastic frontier model is suitable for analysing farm level data where measurement errors are substantial and the weather is likely to have a significant effect (Coelli, 1995). It also allows for the estimation of standard errors as well as to test hypotheses. The stochastic frontier model decomposes the error term into a two-sided random error that captures random effects outside the control of the firm (farmer) and the one-sided inefficiency component. According to Coelli et al. (1998), it is called a stochastic function because the output values are bounded by the stochastic (random) variable $\exp \left(X_{i} \beta+V_{i}\right)$. Furthermore, the random error $V_{i}$ can be positive or negative and therefore the stochastic frontier outputs vary about the deterministic part of the model, $\exp \left(X_{i} \beta\right)$.

The general stochastic model is given as:

$$
Y_{i}=f\left(X_{i} ; \beta\right) \exp \left(V_{i}-U_{i}\right)
$$

where $Y_{i}$ is the output of the ith farmer; $X_{i}$ is a vector of farm inputs; $\beta$ is a vector of parameters to be estimated; $V_{i}$ while measures the random variation in output $\left(Y_{i}\right)$ due to factors outside the control of the farm, are factors within the control of the farm responsible for its inefficiency. $V_{i}$ is assumed to be identically and independently distributed as $N\left(0, \sigma_{v}^{2}\right)$ and independent of $U_{i}$ which has a half normal non-negative distribution. $U_{i}$ is independently, but not identically distributed. The composed error term, $\varepsilon_{i}$, is thus defined as:

$$
\varepsilon_{i}=V_{i}-U_{i}
$$

Jondrow et al. (1982) specified a decomposition method from the conditional distribution of $u$ given $e$. Given the normal distribution of $v$, and the half-normal distribution of $u$, the farm specific conditional inefficiency ( for each observation is derived from the conditional distribution of $u$, where $u=e+v$. Therefore, the conditional mean is: 


$$
E(u / e)=\sigma^{2}\left[\frac{f(e \lambda / \sigma)}{1-F(e \lambda / \sigma)}-\frac{e \lambda}{\sigma}\right]
$$

where $f$ and $F$ represent the standard normal density and cumulative distribution functions, respectively.

$$
\lambda=\sigma_{u} / \sigma_{v}
$$

Equation 5 is the ratio of the two standard errors as used by Jondrow et al. (1982) and it measures the total variation of output from the frontier that can be attributed to technical efficiency. The estimation of $\gamma$ which is the ratio of the variance of $u$ to the total variance is given as:

$$
\gamma=\sigma_{u}^{2} / \sigma_{v}^{2}
$$

$\sigma_{v}^{2}$ and $\sigma_{u}^{2}$ are variance of the stochastic model and the inefficiency model respectively.

Technical efficiency is measured as a ratio of actual to potential output (Aigner et al., 1977; Meeusen \& van den Broeck, 1977). Therefore, the technical efficiency (TE) of a firm is defined as, $T E=\exp \left(-U_{i}\right)$. That is,

$$
T E=\frac{Y_{i}^{*}}{Y_{i}}=\frac{f\left(X_{i} \beta\right) \exp \left(V_{i}-U_{i}\right)}{f\left(X_{i} \beta\right) \exp \left(V_{i}\right)}=\exp \left(-U_{i}\right)
$$

We also adopt the model proposed by Battese and Coelli (1995), in which the technical inefficiency, TI effects are defined by:

$$
U_{i}=Z_{i} \delta+w_{i}
$$

where $Z_{i}$ is a $(1 \times m)$ vector of explanatory variables associated with the TI effects; $\delta$ a $(m \times 1)$ vector of unknown parameters to be estimated; and $w_{i}$ is an unobservable random variable. The parameters indicate the impacts of variables in $Z$ on TE. A negative value suggests a positive influence on $T E$ and vice versa.

The cost efficiency function is specified by changing the error from the $\varepsilon_{i}=V_{i}-U_{i}$ to $\varepsilon_{i}=U_{i}+V_{i}$. Transforming the production function gives us the cost function in a general form as:

$$
C_{i}=f\left(Y_{i}, H_{i} ; \beta\right) \exp \left(U_{i}+V_{i}\right)
$$

where $C_{i}$ is the total cost of production by the $i$ th farmer with a corresponding output, $Y_{i}$ and $H_{i}$ are the vector of observed output and input prices for the $i$ th farm, $\beta$ and is a vector of unknown parameters to be estimated. $V_{i}$ are random variables assumed to be iid $N\left(0, \sigma_{v}{ }^{2}\right)$ and independent of the $U_{i}$ are non-negative variables which are assumed 
to be iid $N\left(0, \sigma_{u}{ }^{2}\right)$ and also responsible for cost inefficiency by determining how far the firm operates above the cost frontier.

Firm specific economic efficiency is then obtained as the ratio of minimum total production cost $\left(C^{*}\right)$ to actual observed total production of cost $(C)$ as follows:

$E E=\frac{C_{i}^{*}}{C_{i}}=\frac{f\left(Y_{i}, H_{i} ; \beta\right) \exp \left(U_{i}+V_{i}\right)}{f\left(Y_{i}, H_{i} ; \beta\right) \exp \left(V_{i}\right)}=\exp \left(U_{i}\right)$

where $C^{*}$ is the production cost under ideal condition where efficiency is achieved and $C$ denotes the actual cost observed from the individual farmer sampled. Economic efficiency ranges between o and 1. A firm is economically efficient if $U_{i}=0$ and thus $C_{i}^{*}=C_{i}$. There is economic inefficiency $(E I)$ if $C_{i}^{*}<C_{i}$.

The farm-specific economic inefficiency $u_{i}$ can also be given as:

$$
U_{i}=K_{i} \delta+w_{i}
$$

where $K_{i}$ is a $(1 \times m)$ vector of explanatory variables associated with the EI effects; $\delta$ is a $(m \times 1)$ vector of unknown parameters to be estimated; and $w_{i}$ is an unobservable random variable. The parameters indicate the effect of variables in $K$ on $E E$. A negative value suggests a positive influence on $E E$ and vice versa.

Relative to $A E$, Farrell (1957), explained that $A E$ index can be obtained from $E E$ values, given that $E E=T E_{i} \times A E_{i}$.

Similarly, an input is allocatively efficient if it is used up to the point where its marginal value product (MVP) is equal to its marginal factor cost (Barnett, 2004; Al-hassan, 2004; Oluwatayo et al., 2008; and Omonona et al., 2010). In order to obtain input-use allocative efficiency estimates, an average response model is estimated using ordinary least squares (OLS) and subjected to further analyses to obtain input elasticities (E) and marginal physical products (MPPs) of the inputs. MPP is calculated by first, taking the derivative $(E)$ with respect to the particular input of the production function. The elasticity of the particular input is then multiplied by the ratio of average output to average input use of the input in question. The MVP of an input is the product of MPP and output price $\left(P_{\mathrm{y}}\right)$. If the unit cost of the input also referred to as marginal factor cost $(M F C)$ is known, then an index $(R)$ for determining allocative efficiency of the input used can be calculated as follows:

$$
\begin{aligned}
& Y=f(X ; \beta) \\
& E_{i}=\frac{\partial \ln Y}{\partial \ln x_{i}}
\end{aligned}
$$




$$
\begin{aligned}
& M P P=\left(\frac{Y}{\bar{X}}\right) * E \\
& M P P_{X} \cdot P_{y}=M V P=P_{x}
\end{aligned}
$$

If there exists full $A E$ of input $x$ then,

$$
\frac{M V P_{x}}{P_{x}}=R_{x}=1
$$

Consequently, an input is either under-utilized $(R>1)$ or over-utilized $(R<1)$. In order to achieve full allocative efficiency in a situation where $R \neq 1$, then $(1-R)^{*} 100$ gives the extent of change required in the inputs' application (Nwaru \& Iheke, 2010).

\section{Empirical Model of the Stochastic Technical and Cost Functions}

The two commonly used functional forms of the stochastic production function are the Cobb-Douglas and the translog. The Cobb-Douglas functional form is not only simple but it is self-dual and has been applied widely in agricultural production technologies in many developing countries (Bravo-Ureta \& Pinheiro, 1993). The Cobb-Douglas functional form is as follows:

$\ln Y=\beta_{0}+\beta_{1} \ln X_{1}+\beta_{2} \ln X_{2}+\beta_{3} \ln X_{3}+\beta_{4} \ln X_{4}+\beta_{5} \ln X_{5}+V_{i}-U_{i}$

where $\ln$ represents logarithm to base $e ; Y$ is output of maize (in $\mathrm{kg}$ ); $X_{1}$ is farm size in hectares; $X_{2}$ is the quantity of own/purchased seed (kg) used for planting; $X_{3}$ is quantity of fertilizer used in $\mathrm{kg} ; X_{4}$ is the labour quantity and $X_{5}$ quantity of weedicides (in litres).

The associated cost function is expressed as:

$\ln C=\beta_{0}+\beta_{1} \ln Y+\beta_{2} \ln H_{1}+\beta_{3} \ln H_{2}+\beta_{4} \ln H_{3}+\beta_{5} \ln H_{4}+\beta_{6} \ln H_{5}+V_{i}+U_{i}$

where $\ln$ represents logarithm to base $e ; C$ is the total cost of maize production in GHథ; $Y$ is output of maize (in $\mathrm{kg}$ ); $H_{1}$ is unit price of land; $H_{2}$ is unit price of seed; $H_{3}$ is unit price of fertilizer; $\mathrm{H}_{4}$ is unit price of labour and $H_{5}$ unit price of weedicides. Prices are in GHष.

The technical inefficiency model is also given as follows:

$U_{i}=\delta_{0}+\delta_{1} Z_{1}+\delta_{2} Z_{2}+\delta_{3} Z_{3}+\delta_{4} Z_{4}+\delta_{5} Z_{5}+\delta_{6} Z_{6}+\varepsilon_{i}$

where $Z_{1}$ is access to tractor services as proxy to level of agricultural mechanization; $Z_{2}$ is the number of years of farmer in maize cultivation; $Z_{3}$ is number of years in school; $Z_{4}$ is number of agricultural extension visits; and $Z_{5}$ is gender of the farmer (categorized as 1 for males and o for females); $Z_{6}$ is the amount of credit received during the cropping season (in $\mathrm{GH} \Phi) ; \varepsilon_{i}$ is the two-sided error term and $\delta_{i}$ is a vector of parameters to be estimated. 
Using similar socio-economic variables, the cost inefficiency model is stated as follows:

$U_{i}=\delta_{0}+\delta_{1} Z_{1}+\delta_{2} Z_{2}+\delta_{3} Z_{3}+\delta_{4} Z_{4}+\delta_{5} Z_{5}+\delta_{6} Z_{6}+\varepsilon_{i}$

Equations (17), (18), (19) and (20) are estimated by maximum likelihood which yields consistent estimators for $\beta, \delta, \gamma$, and $\sigma_{z}^{2}$, where $\gamma=\sigma^{2} / \sigma_{z}^{2}$ and $\sigma_{z}^{2}=\sigma_{v}^{2} / \sigma^{2}$.

The likelihood ratio test is used to determine the relationship between maize output (dependent variable) and input use; and secondly, the relationship between maize output and socioeconomic, institutional and farm-specific factors (explanatory variables) on the other hand. The generalized likelihood-ratio test is of the form:

$k=-2\left[\ln \left\{L\left(H_{A}\right)\right\} / \ln \left\{L\left(H_{0}\right)\right\}\right]=-2\left[\ln \left\{L\left(H_{A}\right)\right\}-\ln \left\{L\left(H_{0}\right)\right\}\right]$

where $L\left(H_{A}\right)$ and $L\left(H_{0}\right)$ are the values of the likelihood function under the alternative and null hypotheses. The value $k$ of has a chi-square, $\chi^{2}$ (or mixed chi-square) distribution with the number of degrees of freedom equal to the difference between the number of parameters involved in $H_{0}$ and $H_{A}$.

\section{Empirical Specification of the Allocative Efficiency Model}

The $A E$ of the production inputs is determined by estimating an average response model using OLS. From the average production functions, factor elasticities $(E)$ and marginal physical products (MPPS) of the various inputs are calculated. Elasticity $(E)$, is given by:

$\operatorname{Land}\left(X_{1}\right)=\frac{\partial \ln Y}{\partial \ln X_{1}}=\beta_{1} ; \operatorname{Seed}\left(X_{2}\right)=\frac{\partial \ln Y}{\partial \ln X_{2}}=\beta_{2} ;$ Fertilizer $\left(X_{3}\right)=\frac{\partial \ln Y}{\partial \ln X_{3}}=\beta_{3} ;$

$\operatorname{Labour}\left(X_{4}\right)=\frac{\partial \ln Y}{\partial \ln X_{4}}=\beta_{4} ;$ Weedicides $\left(X_{5}\right)=\frac{\partial \ln Y}{\partial \ln X_{5}}=\beta_{5}$

\section{Results and Discussion}

\section{Demographic Characteristics of Respondents}

The mean age of about 41 years in the study area revealed that, a typical farmer was within the economically active age bracket as the national description includes people between 15 to 60 years of age. The study found a higher mean household size of 8.66 compared with 6.56 obtained in the 2010 census by the Ghana Statistical Service (GSS) for northern Ghana. The mean household size reported in this study was also twice the national average of 4.4 (GSS, 2012). Meanwhile, the mean household labour of 5.75 was equally less than the average household size. This meant that the number of people in the household that could offer farm labour was far less than the household members. The discrepancy between household size and household labour has implications for farm 
labour especially in northern Ghana where household heads rely on their households to provide labour for almost all of their crop production activities and when it was not sufficient, hired labour was sought. This also implies that households had more dependants, at least 3 dependants per household in the study area. Nonetheless, this dependency ratio of 1:3 is lower than the national mean value of 1:4 recorded in the 2010 census (GSS, 2012). The average farm size of 3.21 hectares further reinforces the fact that the majority of rural farm households were indeed operating with quite smaller land holdings. Similarly, Nyanteng and Seini (2000) also stated that over 90\% of the country's food production came from farm holdings of 3 hectares or less. The mean quantity of maize seed used in cultivation was $30.75 \mathrm{~kg}$ as presented in Table 1 . This implies that a household would need this to sow 3.21 hectares (about 7.8 acres) of land.

Table 1: Descriptive statistics of variables

\begin{tabular}{|c|c|c|c|c|c|}
\hline Variable & Description & Min. & Max. & Mean & $\begin{array}{l}\text { Std. } \\
\text { Dev. }\end{array}$ \\
\hline Age & Number of years of respondents & 18 & 79 & 40.89 & 11.42 \\
\hline Sex of respondent & Dummy; o for female, 1 for male & o & 1 & 0.85 & 0.36 \\
\hline Educational status & Number of years of formal education & o & 16 & 4.66 & $5 \cdot 74$ \\
\hline Farm size (ha) & Number of hectares of cultivated maize & 0.2 & 24.28 & 3.21 & 5.10 \\
\hline Experience & Number of years in maize cultivation & 1 & 40 & 8.72 & 6.94 \\
\hline Household size & Number of members in household & 2 & 35 & 8.66 & 6.92 \\
\hline Household labour & $\begin{array}{l}\text { Household members who work on the } \\
\text { farm }\end{array}$ & 1 & 21 & $5 \cdot 75$ & 5.28 \\
\hline Maize seed & $\begin{array}{l}\text { Quantity of maize seed }(\mathrm{kg}) \text { used in } \\
\text { sowing }\end{array}$ & $3 \cdot 3$ & 198 & 30.75 & 23.61 \\
\hline Weedicides & Quantity of weedicides (in litres) used & o & 36 & 5.11 & 5.40 \\
\hline Fertilizer use & Quantity of chemical fertilizer (kg) used & o & 3000 & 451.32 & 420.92 \\
\hline Maize output & Quantity of maize $(\mathrm{kg})$ harvested & 50 & 18000 & $2099 \cdot 9$ & 2375.79 \\
\hline Maize price & Price in $\mathrm{GH} ₫$ per kg & 0.4 & 0.8 & 0.588 & 0.801 \\
\hline Credit & $\begin{array}{l}\text { Value of credit received (in } \mathrm{GH} \Phi \text { ) to } \\
\text { support maize cultivation during the } \\
\text { season }\end{array}$ & o & 2000 & 16.16 & 118.02 \\
\hline Price of land & Rental value (in $\mathrm{GH} ₫$ ) per ha of land & o & 148.23 & 98.71 & 23.76 \\
\hline Cost of seed & Amount paid (in $\mathrm{GH} \uparrow$ ) per $\mathrm{kg}$ of seed & 0.61 & 3.03 & 0.90 & 0.38 \\
\hline Cost of fertilizer & Amount paid (in $\mathrm{GH} \pitchfork$ ) per kg of fertilizer & o & 1.25 & 0.98 & 0.22 \\
\hline Price of labour & Amount paid (in $\mathrm{GH}_{4}$ ) for labour & o & 70 & $29 \cdot 51$ & 16.76 \\
\hline Price of weedicides & $\begin{array}{l}\text { Amount paid (in } \mathrm{GH} \Phi \text { ) per litre of } \\
\text { weedicides }\end{array}$ & 0 & 10 & 6.19 & $3 \cdot 38$ \\
\hline
\end{tabular}

Source: Authors' Computation, 2015 
Similarly, a household on average required 5.11 litres ( 5.11 bottles) of weedicides to apply on 3.21 hectares of farm land to control weeds. The mean quantity of chemical fertilizers used was $451.32 \mathrm{~kg}$ (about 9 bags of 5okg each). A household therefore used about 6 bags of NPK and 3 bags of Ammonia fertilizer to apply on a 3.21 hectare plot in order to obtain an average output of about 3oookg (about 30 bags) of maize.

A household on average received a credit amount of GHథ 16.2, which was woefully inadequate to support maize production. Access to credit to support and enhance food production remains a major challenge to small scale farmers. Finding the cash to buy inputs such as fertilizer and hire machinery could be the first hurdle for a farmer seeking to scale up production. Formal financial systems are reluctant to offer credit to smallholder farmers because of perceived risks and lack of collateral. In this study, 92.5\% of respondents did not have access to credit facilities to enable them purchase production enhancing inputs to increase their maize output.

Borrowing from relatives, friends and traders were the common sources of credit for households as opposed to formal sources. Esteban and Diao (2011) found traders to be an important source of agricultural credit in the rural areas. They lend to households who need money to pay for inputs such as hired labour or fertilizer, prior to harvest in return for their products (maize). It was also the case in this study, where some farmers borrowed money from traders with the promise of paying back in kind (with maize) soon after harvesting.

\section{Tests of Hypotheses}

The generalized likelihood ratio test was used to establish the role of socio-economic indicators in explaining technical inefficiency as shown in Table 2.

Table 2: Test of hypothesis for presence of inefficiency term

\begin{tabular}{|c|c|c|c|c|}
\hline Null Hypothesis & $\begin{array}{l}\text { Log Likelihood } \\
\text { Function }\left(\mathrm{H}_{\mathrm{o}}\right)\end{array}$ & $\begin{array}{l}\text { Test Statistic } \\
\Lambda\end{array}$ & Critical Value & Decision \\
\hline$H_{0}: \delta_{1}=\ldots=\delta=0$ & -332.01 & 43.63 & $12.592(6)$ & Reject $\mathrm{H}_{\mathrm{o}}$ \\
\hline
\end{tabular}

Critical values are at $5 \%$ significance level and obtained from $\chi^{2}$ distribution table. Figures in brackets are the number of restrictions.

\section{Determinants of Output, Production Cost, Technical and Cost Inefficiency}

In this section, we discuss the determinants of maize output, production cost, technical and cost inefficiency for the study area. All the variables with the exception of labour 
had positive effect on maize output and also statistically significant (see Table 3). For example, the coefficient of farm size which was 0.134 means that when farm size increased by $100 \%$, holding all other inputs constant, output would increase by about $13 \%$. Regarding the determinants of production cost, all the variables (land, seed, fertilizer, labour and weedicides cost) had positive and statistically significant effect on total production cost. For instance, the coefficient of fertilizer cost of 0.308 could be interpreted as when fertiliser cost increases by $100 \%$, holding all other inputs prices constant, total production cost rises by about $31 \%$. The coefficient of weedicides cost (o.039) also means that an increase in its cost by $100 \%$, holding all other inputs prices constant, would push total production cost up by about $4 \%$.

The value of 0.961 of the gamma for the production function was statistically significant at $5 \%$, suggesting that technical inefficiency had significant effect on output (Wadud \& White, 2000; Sharma et al. 1997; Hjalmarsson et al., 1996). This means that $96.1 \%$ of the total variation in output was as a result of factors within the control of the farmer and that variation in maize output could be attributed to inefficiency. This could also be interpreted to mean that the differences between actual (observed) and frontier output were dominated by technical inefficiency (i.e., factors within the control of the farmers rather than outside their control). The remaining $3.9 \%$ was due to factors outside the control of the farmers. The gamma value of 1.735 for the cost inefficiency means that about $74 \%$ of total cost of production resulted from inefficiency. That is the cost to the firm for being technically inefficient. 
Table 3: Maximum likelihood estimates of the stochastic frontier models

\begin{tabular}{|c|c|c|c|}
\hline \multirow{2}{*}{ Variable } & \multirow{2}{*}{ Parameter } & \multicolumn{2}{|c|}{ Coefficients (Stan. Error) } \\
\hline & & Production frontier & Cost frontier \\
\hline Constant & & $4.099(0.184)$ & $1.612(0.089)$ \\
\hline Farm size & & $0.134(0.054)^{* *}$ & $0.364(0.015)^{* * *}$ \\
\hline Seed & & $0.646(0.057)^{* * *}$ & $0.121(0.019)^{* * *}$ \\
\hline Fertilizer & & $0.156(0.023)^{* * *}$ & $0.308(0.006)^{* * *}$ \\
\hline Labour & & $0.017(0.018)$ & $0.072(0.009)^{* * *}$ \\
\hline Weedicides & & $0.075(0.020)^{* * *}$ & $0.039(0.009)^{* * *}$ \\
\hline \multirow[t]{2}{*}{ Output } & & & $0.045(0.014)^{* *}$ \\
\hline & & Technical inefficiency & Cost inefficiency \\
\hline Constant & $\delta_{0}$ & $0.782(0.772)$ & -2.478 (o.349) \\
\hline Agric. mech. & $\delta_{1}$ & $-0.715(0.626)$ & $0.046(0.281)$ \\
\hline Experience & $\delta_{2}$ & $-0.139(0.69)^{* *}$ & $0.026(0.012)^{* *}$ \\
\hline Education & $\delta_{3}$ & $0.015(0.044)$ & $-0.007(0.015)$ \\
\hline Extension & $\delta_{4}$ & $-2.590(1.563)^{*}$ & $0.390(0.092)^{* * *}$ \\
\hline Gender & $\delta_{5}$ & $-0.975(0.537)^{*}$ & $0.171(0.238)$ \\
\hline Credit & $\delta_{6}$ & $-0.000(0.003)$ & $0.000(0.000)$ \\
\hline Sigma squared & & $-1.220(0.086)^{* * *}$ & $-5.752(0.143)^{* * *}$ \\
\hline Gamma & & $0.961(0.134)^{* *}$ & $1.735(0.953)^{* * * *}$ \\
\hline Mean efficiency & \multicolumn{3}{|l|}{0.8501 .472} \\
\hline Returns to scale & \multicolumn{3}{|l|}{1.028} \\
\hline Log-likelihood function & \multicolumn{3}{|c|}{$-310.19511 .893$} \\
\hline
\end{tabular}

${ }^{* * *},{ }^{* *} \&{ }^{*}$ indicates values statistically significant at $1 \%, 5 \%$ \& $10 \%$ respectively. Figures in brackets are the standard errors.

Source: Authors' Computation, 2015

The sigma squared value of 1.220 was significantly different from zero at $1 \%$ and indicated the correctness of the specified distributional assumption for the inefficiency term, . The returns to scale value of 1.028 indicated increasing returns to scale. This means that maize production in the study area was in stage one of the production function and therefore inputs were on average being under-utilised. Therefore, an 
increase in the use of the variable inputs in the production process would lead to a more than proportionate increase in output.

The sources of inefficiency are discussed using the estimated $(\mathbb{Q})$ coefficients associated with the inefficiency effects in Table 3. Variables with negative coefficients have negative relations with inefficiency. The opposite is the case for variables with positive coefficients.

The socio-economic variables employed to explain technical inefficiency were access to agricultural mechanization, experience, educational status, access to agricultural extension services, gender of maize farmer and access to credit. To begin with, the negative sign of experience which is also statistically significant at $5 \%$ in the inefficiency model gives an indication that farmers who had been in maize cultivation for many years were more technically efficient. This could also be interpreted as farmers with many years of experience were more technically efficient than those with few years. Nonetheless, the more experienced maize farmers were not cost efficient. This finding is consistent with Donkoh et al. (2013) who found experience to be significant in determining the efficiency of tomato farmers at the Tono irrigation scheme in the Upper East region. Okike et al. (2004) further emphasized that experience is an important factor that contributes to technical efficiency because of expected acquisition of dexterity in doing the same task over a period of time in this case maize cultivation. Lapple (2010) also made the argument that an increase in farming experience provides better knowledge about the production environment in which decisions are made. Given the relative importance of experience in maize cultivation, opportunities (nucleus farms and farmer field schools) that bring the less experienced farmers to tap the accumulated knowledge of the more experienced farmers would improve maize production. On the contrary, Oyewo (2009) found maize farmers with many years of experience to be less technically efficient in Ogbomoso South local government area in Nigeria.

In line with a priori expectation, the coefficient of agricultural extension was negative and statistically significant at $10 \%$. Farmers who had access to agricultural extension services were more technically efficient than those without access to agricultural extension. However, their access to extension service did not make them cost efficient. Agricultural extension agents focus on imparting key messages to farmers with the aim of improving production techniques including land preparation, use of improved crop varieties, crop spacing as well as the timeliness of operations such as weeding, pest control and fertilizer application. According to Evenson (2001) and Gautam (2000), a well-functioning agricultural extension system is pivotal to increasing the productivity of staple food crops and thus presents a credible avenue for moving millions of people out of poverty. The World Development Report (World Bank, 2008) further emphasized the importance of agricultural extension service in the dissemination of technologies 
adapted to African conditions so as to spur an African green revolution if it is given the necessary institutional support. It can contribute to the reduction of the productivity differential by increasing the speed of technology transfer. This is because agricultural extension provides the means by which information on new technologies, better farming practices and management skills can be transmitted to farmers. Agricultural research findings would be meaningless unless they are accepted and adopted by farmers who are the end-users of the research output and this adoption is facilitated by agricultural extension workers.

The gender of maize farmer had a negative sign and was marginally significant (at 10\%). Male farmers were more technically efficient than their female counterparts. Therefore, gender plays a significant role in determining technical efficiency of maize production in northern Ghana. Donkoh et al. (2013b) also found gender statistically significant with male tomato farmers being more technically efficient than their female counterparts at the Tono Irrigation site in the Upper East region of Ghana. Women farmers generally have lower educational levels which affect their understanding and adoption of modern production technologies especially if these technologies require the use of more technical and intensive knowledge (Ragasa, 2012). The socio-cultural setting of an area plays an important role in determining the productivity of each gender. Women perform crucial roles in the domestic and economic life of society which affect their technical efficiency. In this study for example, female farmers helped in sowing, fertilizer application and food preparation among others on their husbands' farms even when they had to be working on their own maize plots.

The other socio-economic variables such as the level of formal education, credit and agricultural mechanization were not statistically significant in this study.

\section{Allocative Efficiency}

This section examines the allocative efficiency of maize production in the study area by measuring how the farmers allocate expenditure on land, seed, fertilizer, labour and weedicides with respect to input quantities under the given production technology. This was achieved by estimating an average production function from which input elasticities $(E)$, marginal value products (MVP), marginal factor cost $(M F C)$ and allocative ratios $(R)$ of the inputs were calculated (Table 4 ). The results show that the allocative efficiency ratio $(R)$ for land is greater than 1 . This means that land is being under-utilized because the marginal value obtained from spending GH 74.26 on land is less than its marginal value product of GH $\$ 98.08$. For land to be allocatively efficient, its use should be increased by $26.6 \%$ to reach the point at which its $M V P$ equals it $M F C$. 
Table 4: Allocative efficiency ratios $(R)$ of the various production inputs

\begin{tabular}{|l|l|l|l|l|}
\hline Input & $M V P$ & $M F C$ & $R=M V P / M F C$ & \% change required \\
\hline Land & 94.08 & 74.26 & 1.27 & -26.60 \\
\hline Seed & 10.39 & 0.90 & 11.54 & -10.54 \\
\hline Fertilizer & 0.17 & 0.98 & 0.17 & +82.80 \\
\hline Labour & 3.99 & 73.05 & 0.05 & +94.54 \\
\hline Weedicides & 8.55 & 6.20 & 1.38 & -37.90 \\
\hline
\end{tabular}

(-) implies increased use is needed and (+) means reduction is needed.

Similarly, seed use has an allocative efficiency ratio above 1 which implies there is the need to increase seed use. The marginal factor cost of GH 0.90 spent on seed is less than its marginal value product of 10.39. In order to achieve allocative efficiency, seed use should be increased by $10.54 \%$ to reach the point at which its MVP equals its MFC. Likewise, weedicides has an allocative efficiency of 1.38 meaning that it is currently being under-utilized with the possibility of it being increased by $37.9 \%$ to attain allocative efficiency.

On the other hand, fertilizer has an allocative efficiency of less than 1 (0.17). This can be interpreted to mean that fertilizer is being over-used and quantity used would have to reduce by $82.80 \%$ to attain allocative efficiency given the MVP of 0.17 and MFC of 0.98 . Similar interpretation can be given to labour which has an allocative efficiency ratio of 0.05 and would require a $94.5 \%$ reduction in labour quantity in order to reach allocative efficiency.

\section{Distribution of Efficiency Estimates}

The mean technical efficiency of maize production in the study area was $85.1 \%$ with maximum and minimum values of $99.8 \%$ and $22.1 \%$ respectively (see Table 5). The mean technical efficiency value of about $85 \%$ means that maize farmers only attained an output equal to $85 \%$ of potential output and they could get an additional output of $15 \%$ if the technical inefficiency in production is eliminated. The mean allocative efficiency was $87.8 \%$ and could be interpreted to mean that farmers were about $88 \%$ efficient in input use relative to input prices. Economic efficiency which is the product of technical and allocative efficiency had a mean of $74.7 \%$. 
Table 5: Summary of efficiency estimates

\begin{tabular}{|l|l|l|l|l|}
\hline Efficiency type & Mean & Maximum & Minimum & Std dev. \\
\hline Technical eff. & 0.851 & 0.998 & 0.221 & 0.147 \\
\hline Allocative eff. & 0.878 & 0.978 & 0.602 & 1.170 \\
\hline Economic eff. & 0.747 & 0.976 & 0.133 & 0.172 \\
\hline
\end{tabular}

Source: Author's Computation, 2015

Economic efficiency measures the extent to which farmers make efficient decisions by using inputs up to the level at which their marginal value products equal their marginal factor costs while obtaining maximum output from a given set of inputs under the given production technology.

As regards the distribution of efficiency estimates across the various efficiency types, half of the maize farmers had technical efficiency within the 0.9 to 1.00 (Table 5). Likewise, they also reported higher allocative efficiencies with a little over half (50.5\%) falling within the 0.90 to 1.00 bracket.

Table 5: Efficiency estimates distribution

\begin{tabular}{|l|l|l|l|}
\hline Efficiency range & TE & AE & EE \\
\hline 0.5 & 3.3 & 7.2 & 9.7 \\
\hline $0.51-0.60$ & 3.1 & 8.9 & 11.4 \\
\hline $0.61-0.70$ & 11.7 & 8.6 & 10.6 \\
\hline $0.71-0.80$ & 13.6 & 11.4 & 22.5 \\
\hline $0.81-0.90$ & 18.3 & 13.3 & 29.2 \\
\hline $0.91-1.00$ & 50.0 & 50.5 & 16.7 \\
\hline Total & 100.0 & 100.0 & 100.0 \\
\hline
\end{tabular}

Source: Authors' Computation, 2015

However, economic efficiency was higher than average with about $29 \%$ and $23 \%$ recording scores around 0.81 to 0.90 and 0.71 to 0.80 respectively as presented in Table 5 .

\section{Conclusions and Recommendations}

This study employed the stochastic frontier model to examine the technical and allocative efficiencies of maize production in northern Ghana using cross-sectional data for the 2011/2012 cropping season. Farm size, seed, fertilizer, labour and weedicides were statistically significant and had positive effect on both maize output and total production cost in northern Ghana. The mean estimates were $85.1 \%, 87.8 \%$ and $74.7 \%$ 
for technical, allocative and economic efficiencies respectively. The determinants of technical inefficiency were experience, agricultural extension service and gender. Farmers with many years of experience in maize production were more technically efficient than the less experienced ones and therefore, opportunities such as nucleus farms and farmer field schools that bring these less experienced farmers to tap the accumulated knowledge of the more experienced ones would improve maize production. Farmers who had access to agricultural extension services were more technically efficient than those who did not have. Government, through MoFA, should strengthen the agricultural extension system to provide quality extension services to farmers so as to enable them improve on their technical efficiency. Additionally, male farmers were more technically efficient than females in maize cultivation and efforts should be made to narrow this gap. Governmental and non-governmental bodies as well as gender practitioners need to work on advocacy, raising awareness and lobbying to correct the traditions and the wrong perceptions about women to bring change. Largely, maize production in northern Ghana exhibited increasing returns to scale.

There is allocative inefficiency relative to all the production inputs under the prevailing prices. For land, seed and weedicides to be allocatively efficient, their use should be increased by $26.6 \%, 10.52 \%$ and $37.9 \%$ respectively to reach the point at which their MVP equals $M F C$. Fertilizer and labour are currently being over-used and require $82.8 \%$ and 94.5\% reductions respectively to reach their allocatively efficient points.

\section{References}

Abdoulaye, T., Bamire, A.S., Wiredu, A.N., Baco, M.N. and Fofana, M. (2011). Characterization of Maize Producing Communities in Bénin, Ghana, Mali and Nigeria. West Africa Regional Synthesis Report. Drought Tolerant Maize for Africa (DTMA).

Abdulai, A., and Huffman, w. (2000). Structure Adjustment and Economic Efficiency of Rice Farmers in Northern Ghana. Economic Development and Cultural Change, pp. 503-519.

Aigner, D. J., and Chu, S. F. (1968). On estimating the industry production function. American Economic Review, 58(4), pp. 826-839.

Aigner, D.J., Lovell, C.A.K. and Schmidt, P. (1977). Formulation and estimation of stochastic frontier production function models. Journal of Econometrics 6, pp. 21-37.

Akramov, K. and Malek, M. (2012). Analyzing Profitability of Maize, Rice, and Soybean Production in Ghana: Results of PAM and DEA Analysis. Ghana Strategy Support Program (GSSP) Working Paper. 
Al-hassan S. (2004). Farm-Specific Technical Efficiency, Resource Use and Employment: An Analysis of Smallholder Rice Farmers in the Upper East Region of Ghana. Thesis submitted to the University of Ghana, Legon for the award of Doctor of Philosophy Degree in Agricultural Economics.

Barnett, W. (2004) “Dimensions and Economics: Some Problems. Quarterly Journal of Australian Economics, 7(1), pp. 95-104.

Battese, G.E. and Coelli, T.J. (1995). A model for technical inefficiency effects in a stochastic frontier production function for panel data. Empirical Economics, 20, p $325-332$.

Bravo-Ureta, B. and Pinheiro, A. (1993). Efficiency analysis of developing country agriculture: A review of the frontier Function literature. Agriculture Resource Economic Review, 22, pp. 88-101.

Coelli, T.J., Rao, D S.P. and Battese, G.E. (1998). An Introduction to Efficiency and Productivity Analysis. London: Kluver Academic Publishers.

Coelli, T.J. (1996). A Guide to Frontier Version 4.1: A computer program for Frontier Production Function Estimation, CEPA Working Paper 96/o7.

Donkoh, S.A., Ayambila, S. and Abdulai, S. (2013). Technical efficiency of rice production at the Tono Irrigation Scheme in Northern Ghana. American Journal of Experimental Agriculture, 3(1), pp. 25-42.

Donkoh, S.A., Tachega, M. and Amowine, N. (2013b). Estimating technical efficiency of Tomato Production in Northern Ghana. American Journal of Experimental Agriculture, 3(1), pp. 56-75.

Esteban J. Q. and Diao, X. (2011). Assessing Crop Production and Input Use Patterns in Ghana - What can we learn from the Ghana Living Standards Survey (GLSS5)? International Food Policy Research Institute (IFPRI) Discussion Paper.

Evenson, R. (2001). Economic Impacts of Agricultural Research and Extension. In Gardner, B. and Rausser, G. Handbook of Agricultural Economics, chapter 11.

FAO (2006). Food and Agriculture Organization Statistics. Food and Agriculture Organization, Rome, Italy.

Farrell, M. (1957). The measurement of productivity efficiency. Journal of Royal Statistical Society, 120, pp. 253-290.

Gautam, M. (2000). Agricultural Extension: The Kenyan Experience, an Impact Evaluation. Washington, D.C. The World Bank.

Ghana Statistical Service [GSS] (2012). Summary Report of Final Results; 2010 Population \& Housing Census. 
Hjalmarsson L., Kumbhakar S. and Hesmati A. (1996): DEA, DFA and SFA: A Comparison. Journal of Productivity Analysis, 7, pp. 303-327.

Johnes, J. (2006). Data envelopment analysis and its application to the measurement of efficiency in higher education in the United Kingdom. Economics of Education Review, 25, pp. 273-288.

Kumbhakar, S.C. and Lovell, C.A.K. (2000). Stochastic Frontier Analysis. Cambridge: Cambridge University Press.

Lapple, D. (2010). Adoption and Abandonment of Organic Farming: An Empirical Investigation of the Irish Dry-stock Sector. Journal of Agricultural Economics, 61(3).

Meeusen, W. and Van den Broeck, J. (1977). Efficiency estimation from Cobb-Douglas production functions with composed error. International Economic Review, 18(2), pp. 435-43.

MoFA (2011). Agriculture in Ghana. Facts and Figures. Statistical, Research and Information Division (SRID).

MoFA (2010). Medium Term Agriculture Sector Investment Plan (METASIP). Ministry of Food and Agriculture, Ghana.

Nwaru, J. C. and O. R. Iheke (2010). Comparative analysis of resource use efficiency in rice Production systems in Abia State of Nigeria. Journal of American Sciences, 6:11.

Oluwatayo, I. B., Sekumade A. B. and Adesoji S.A. (2008). Resource use efficiency of maize farmers in rural Nigeria: Evidence from Ekiti State. World Journal of Agricultural Science, 4, pp. 91-99.

Omonona, B.T., Egbetokun, O.A. and Akanbi A.T. (2010). Farmers' resource use and technical efficiency in cowpea production in Nigeria. Economic Analysis \& Policy, 40:1.

Okike, I., Jabbar, M., Manyong, V., Smith, J. and Ehui, s. (2004). Factors affecting farm specific production efficiency in the Savanna zones of West Africa. Journal of African Economies, 13(1), pp. 134-165.

Oyewo, I.0. (2009). Determinants of maize production among maize farmers in Ogbomoso South Local Government in Oyo State. Nigeria Agricultural Journal, 4(3), 144-49.

Ragasa, C. (2012). Gender and Institutional Dimensions of Agricultural Technology Adoption: A Review of Literature and Synthesis of 35 Case Studies. Research paper prepared for presentation at the International Association of Agricultural Economists Triennial Conference, Foz do Iguaçu, Brazil 18-24 August, 2012. 
Seini, A.W. (2002). Agricultural Growth and Competitiveness under Policy Reforms in Ghana. Ghana: ISSER, 61.

Sharma K.R., Leung P. and Zalenski H.M. (1997): Productive efficiency of the swine industry in Hawaii: Stochastic Frontier vs. Data Envelopment Analysis. Journal of Productivity Analysis, 8: pp. 447-459.

Smith, J., Weber, G., Manyong, V.M., and Fakorede, M.A.B. (1997). Fostering sustainable increases in maize productivity in Nigeria. Chapter 8 in Africa's emerging maize evolution, edited by Byerlee, D. \& Eicher, C.K. Lynne Rienner Publishers, London,.

Thirtle, C., Lin, L., and Piesse, J. (2003). The impact of research-led agricultural productivity growth on poverty reduction in Africa, Asia and Latin America. World Development, (12): pp 1959-76.

Wadud A. and White B. (2000). Farm household efficiency in Bangladesh: A Comparison of Stochastic Frontier and DEA Methods. Applied Economics, 32: pp 1665-1673.

World Bank. (2008). World Development Report: Agriculture for Development. New York. Oxford University Press. 